\title{
EFECTO DE MEDIDAS PREVENTIVAS CONTRA LA TOXOPLASMOSIS EN EMBARARAZADAS
}

\author{
María Mercedes Santacruz * Reinaldo Heredia** Augusto Corredor Arjona**
}

La incidencia de la infección por Toxoplasma gondii, fue estudiada en el laboratorio de Parasitología del Instituto Nacional de Salud en los sueros de 1000 mujeres embarazadas, seleccionadas entre las que asistieron al control prenatal en la Caja de Previsión, durante los años de 1987 a 1990.

En los sueros se midieron anticuerpos específicos lgG contra el Toxoplasma gondii, por la técnica de Inmunofluorescencia Indirecta.

El $59 \%$ de las mujeres fueron positivas con títulos entre 1:16 y 1:4.096, cifras que corresponden a las reveladas en el Estudio Nacional de Salud (ENS). El $41 \%$ de la población fue negativa. De estas negativas no se presentó ninguna seroconversión dando una incidencia de 0 en el grupo estudiado.

Las embarazadas fueron instruidas sobre medidas preventivas para evitar la infección durante el embarazo, las cuales mostraron su eficacia, ya que ninguna de las negativas seroconvirtió durante el embarazo. Se recomienda, al lado de la vigilancia serológica, dar educación sobre la prevención de la infección.

\section{INTRODUCCION}

El embarazo es la situación clínico-fisiológica en donde más se ha estudiado los efectos de la toxoplasmosis, ya que por su incidencia y gravedad, la infección trasplacentaria es la que reviste un verdadero problema médico por las graves secuelas que deja en el producto de la concepción.

Toda mujer embarazada que tiene una primoinfección, dependiendo de la época de la gestación y si no es tratada oportunamente, tiene la posibilidad de transmitirla al feto con consecuencias más o menos graves. Es así que la parasitemia materna sólo reviste riesgo al feto, únicamente cuando se presenta en la primoinfección (1).

El cuadro clínico de la toxoplasmosis congénita está en relación, entre otros factores, con el momento del embarazo en que se produce la infección materna. Si ocurre en el inicio del embarazo, parte de la enfermedad del feto ocurrirá en la vida intrauterina y la criatura puede nacer con lesiones cicatrizales. Cuando la infección sucede en el final de la gestación, el recién nacido puede presentar un cuadro de toxoplasmosis de diferentes tipos, o nacer asintomático.

\footnotetext{
* Instituto Nacional de Salud, Grupo de Parasitología, Santafé de Bogotá, Colombia

** Caja Nacional de Previsión, Departamento de Ginecoobstetricia

*** Universidad Nacional de Colombia, Facultad de Medicina
} 
En una población dada, la probabilidad de que una mujer se infecte durante su embarazo está en relación con el índice de prevalencia de la toxoplasmosis durante la edad fértil.

En Colombia, Restrepo en 1976 (2) realizó el primer trabajo sobre incidencia de toxoplasmosis congénita en un grupo de 120 mujeres embarazadas, y mostró que el $8.3 \%$ de esta población presentó seroconversión. En la Clínica David Restrepo en Bogotá (3) durante los años de 1978 a 1980 entre 1.320 pacientes se observó una incidencia de seroconversión del $1.35 \%$.

Basados en estos estudios y en comunicaciones del Instituto Materno Infantil, que sirvieron como patrones ya que por razones éticas no podíamos someter a una población al riesgo de adquirir toxoplasmosis congénita, se realizó el presente trabajo, para observar los efectos que conlleva la prevención sobre la incidencia de la toxoplasmosis y así adoptar una política sanitaria educativa para prevenir el riesgo de la toxoplasmosis congénita.

\section{MATERIALES Y METODOS}

La población estudiada estuvo conformada por 1.000 maternas de las que acuden al control prenatal al servicio de ginecoobstetricia de la Caja Nacional de Previsión.

Estas pacientes eran mujeres embarazadas en edades comprendidas entre los 18 y 46 años con un promedio de 24 años.

A todas las pacientes que en la primera muestra presentaron reactividad a cualquier dilución, se les citó a los 20 días para un nuevo control, con el objeto de ver si había estabilidad o aumentos en los títulos, y si así fuera, tomar las medidas pertinentes. A las no reactivas se les entregaba un instructivo con medidas preventivas debidamente explicadas para evitar contaminarse con el Toxoplasma gondii durante el embarazo. Estas maternas fueron controladas cada dos meses hasta finalizar su embarazo.

Para el examen serológico se tomaron $5 \mathrm{ml}$ de sangre total, se centrifugó a 800 g., se separó el suero en alícuotas y se guardó a $-20^{\circ} \mathrm{C}$. Con estos sueros se realizaron pruebas de anticuerpos contra el Toxoplasma gondii IgG, por la técnica de inmunofluorescencia indirecta (4), en el laboratorio de Parasitología del Instituto Nacional de Salud, que tiene como referencia el Centro para el Control de Enfermedades (CDC) de Atlanta, Georgia, y ha obtenido calificación de idoneidaddel $100 \%$.

1. Antígeno: el antígeno se obtuvo a partir de ratones blancos suizos de $20 \mathrm{~g}$ de peso, que fueron inoculados con la cepa $\mathrm{RH}$ de Toxoplasma gondii, que se mantiene crioconservada en el laboratorio de Parasitología del Instituto Nacional de Salud.

Los taquizoitos purificados (4) y diluidos a una concentración de 20 a 30 por campo con objetivo de $40 \mathrm{X}$, se distribuyeron en las respectivas áreas delimitadas de las láminas de inmunofluorescencia y se fijaron a $37^{\circ} \mathrm{C}$ por 30 minutos. Se empacaron y se guardaron en el congelador a $-20^{\circ} \mathrm{C}$.

2. Conjugado: se utilizó el suero inmune anti-IgG humano producido en cabra y conjugado con el isotiocianato de fluoresceina, el cual fue preparado por el grupo de Inmunología del Instituto Nacional de Salud (5).

3. Medidas preventivas contra la toxoplasmosis Se elaboró el siguiente instructivo el cual se le entregaba a la paciente debidamente explicado:

- Evitar comer carne cruda. Las carnes deben ser cocidas a una temperatura no menor de $70 \mathrm{oC}$ para eliminar los quistes del Toxoplasma. (Cocerla hasta que la car ne cambie de color).

- Lavarse las manos después de manipular carne cruda.

- Las mujeres embarazadas deben utilizar guantes cuando manipulen tierras o hagan limpieza del recipiente donde se defeque el gato o a cambio lavarse las manos apenas terminen de cogerla. 


\section{RESULTADOS}

Las pacientes que acudieron al primer control prenatal estaban entre las edades de 18 a 46 años y presentaban embarazo de 5 a 14 semanas, como se muestra en el gráfico 1 .

El gráfico 2 muestra que la mayor fertilidad del grupo de mujeres estudiado se encuentra en las edades de 25 a 34 años en un $67.9 \%$

En las 1.000 pacientes examinadas se halló que el 59\% eran positivas en las diluciones $1: 16$ a $1: 4.096$ y que la población a riesgo era del $41 \%$ tal como muestra el gráfico 3 .

De las 410 maternas a riesgo que constituyeron el $41 \%$ de las pacientes examinadas, sólo llegaron al tercer control 166, que representaban el $40 \%$ deí total de la población a riesgo. $\mathrm{El}$ $60 \%$ de la población a riesgo no llegaron al tercer control debido a la operatividad de la toma de las muestras que hacían depender los controles de la fecha en que iniciaban su primer control. Las 166 maternas con todos los controles y que representaron el $40 \%$ de la población a riesgo permanecieron negativas, es decir, no hubo una seroconversión en el transcurso de seis meses, cuadro 1, contrastando con los estudios de Restrepo (2) donde se presentó un $8.3 \%$ de seroconversión.

Entre el primero y el segundo examen hubo poca variación, las pacientes con títulos de $1: 256$, que representaron el $40.6 \%$ de la población estudiada permanecieron estables, 3 pasaron de 1:64 a 1:256 y dos una de 1:64 y otra de 1:256 se negativisaron, el resto de las pacientes permanecieron estables, cuadro 2 .

Finalmente tenemos que la frecuencia de los títulos es similar a la de la población general como lo muestra el gráfico 4 y los datos de la ENS realizada entre 1977 y 1980 (6).

\section{GRAFICO 1. ASISTENTES A CONTROL PRENATAL SEGUN EDAD CAJANAL BOGOTA 1987-1990}

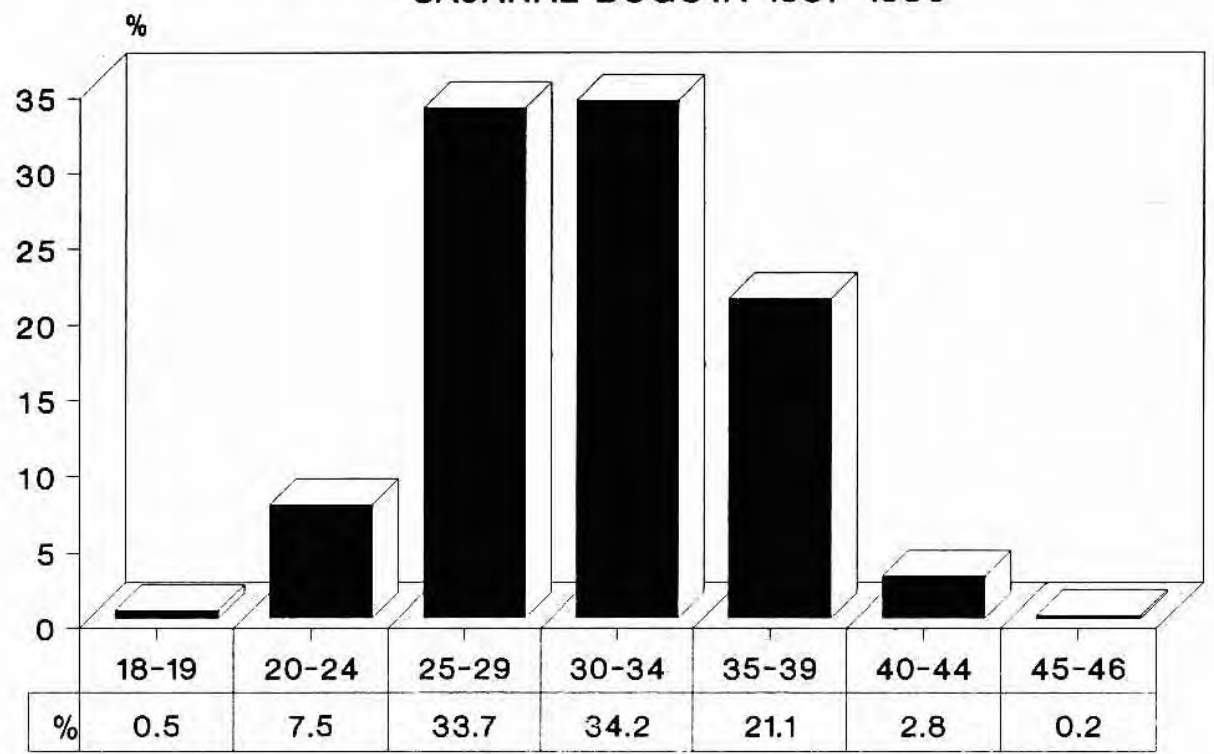

GRUPOS DE EDAD 
INSTITUTO NACIONAL DE SALUD

CAJA NACIONAL DE PAEVIBION

GRAFICO 2. ASISTENTES A CONTROL PRENATAL POR EDAD Y SEMANAS No. DE EMBARAZO. CAJANAL BOGOTA 1987-1990

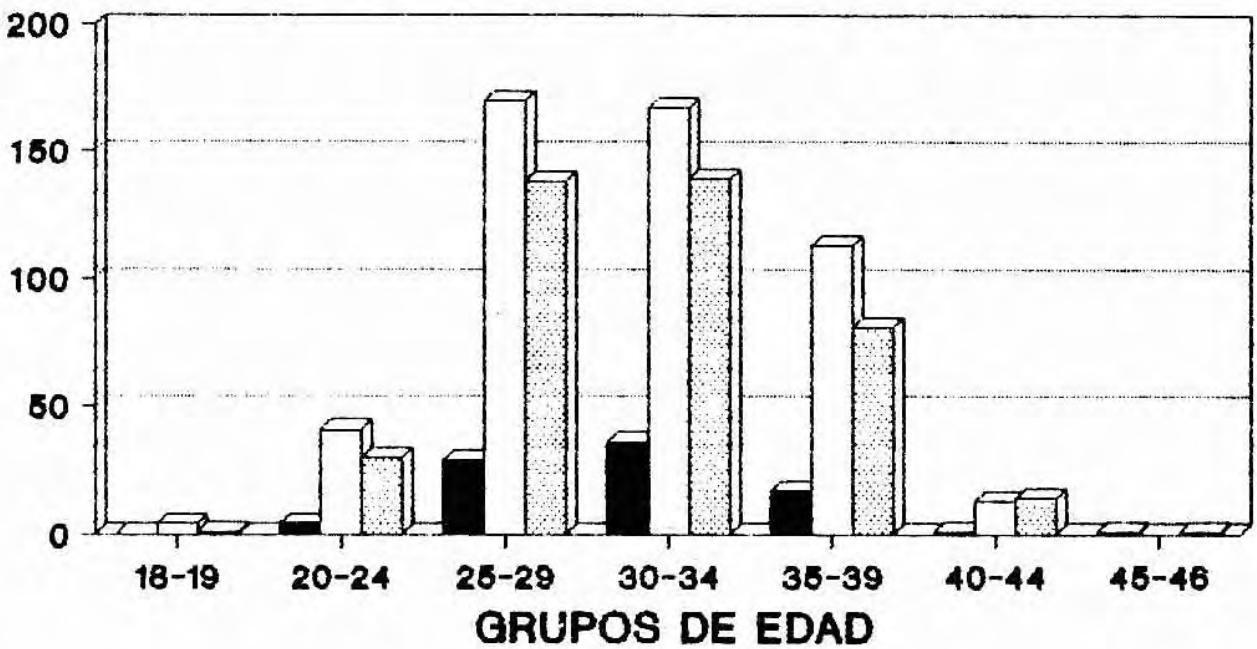

SEMANAS DE EMBARAZO

0-4 [- $]_{6-9} \square 10-14$

INSTITUTO NACIONAL DE SALUD

CAJA NACIONAL DE PREVISION

GRAFICO 3.ANTICUERPOS CONTRA TOXOPLASMA GONDII EN MUJERES EMBARAZADAS.CAJANAL BOGOTA 1987-1990

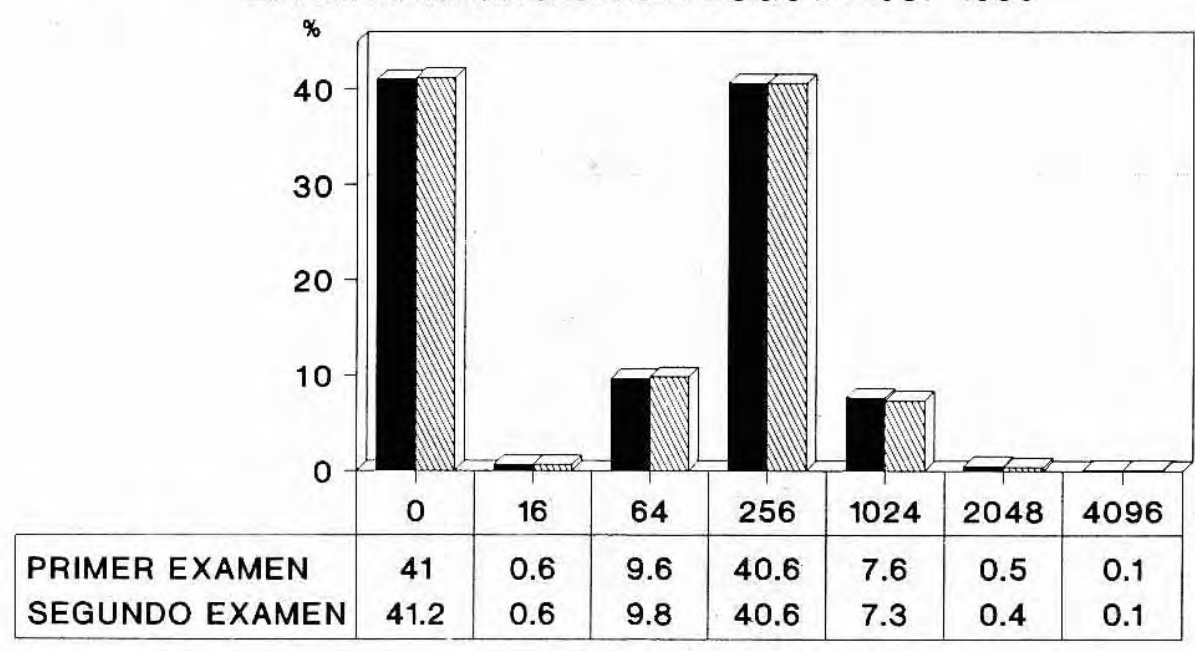

DILUCIONES 
EFECTO DE MEDIDAS PREVENTIVAS CONTRA LA TOXOPLASMOSIS, . . . .

CUADRO 1

AN IICUERPOS CONTRA TOXOPLASMA GONDII EN ASISTENTES A CONTROL PRENATAL CAJANAL-BOGOTA-1987 - 1990.

RESULTADO PRIMER EXAMEN SEGUNDO EXAMEN TERCER EXAMEN

No. $\%$ No. $\%$ No. $\%$

\begin{tabular}{rrrrrrr}
\hline 0 & 410 & 41.0 & 412 & 41.2 & 166 & 98.2 \\
16 & 6 & 0.6 & 6 & 0.6 & & \\
64 & 96 & 9.6 & 98 & 9.8 & & \\
256 & 406 & 40.6 & 406 & 40.6 & 3 & 1.8 \\
1024 & 76 & 7.6 & 73 & 7.3 & & \\
2048 & 5 & 0.5 & 4 & 0.4 & & \\
4096 & 1 & 0.1 & 1 & 0.1 & &
\end{tabular}

CUADRO NO. 2

ANTICUERPOS CONTRA TOXOPLASMA GONDII EN ASISTENTES A CONTROL PRENATAL CAJANAL $1987-1990$

\begin{tabular}{|c|c|c|c|c|c|c|c|c|}
\hline \multirow{2}{*}{$\begin{array}{l}\text { PRIMER } \\
\text { EXAMEN }\end{array}$} & \multirow[b]{2}{*}{0} & \multicolumn{7}{|c|}{ SEGUNDO EXAMEN } \\
\hline & & 16 & 64 & 256 & 1024 & 2048 & 409 & TOTAL \\
\hline 0 & 410 & & & & & & & 410 \\
\hline 16 & & 6 & & & & & & 6 \\
\hline 64 & 1 & & 92 & 3 & & & & \\
\hline 256 & 1 & & 6 & 399 & & & & 406 \\
\hline 1024 & & & & 4 & 72 & & & 76 \\
\hline 2048 & & & & & 1 & 4 & & 5 \\
\hline 4096 & & & & & & & 1 & 1 \\
\hline TOTAL & 412 & 6 & 98 & 406 & 73 & 4 & 1 & 1000 \\
\hline
\end{tabular}

\section{GRAFICO 4. ANTICUERPOS CONTRA TOXOPLASMA GONDII EN MUJERES EMBARAZADAS}

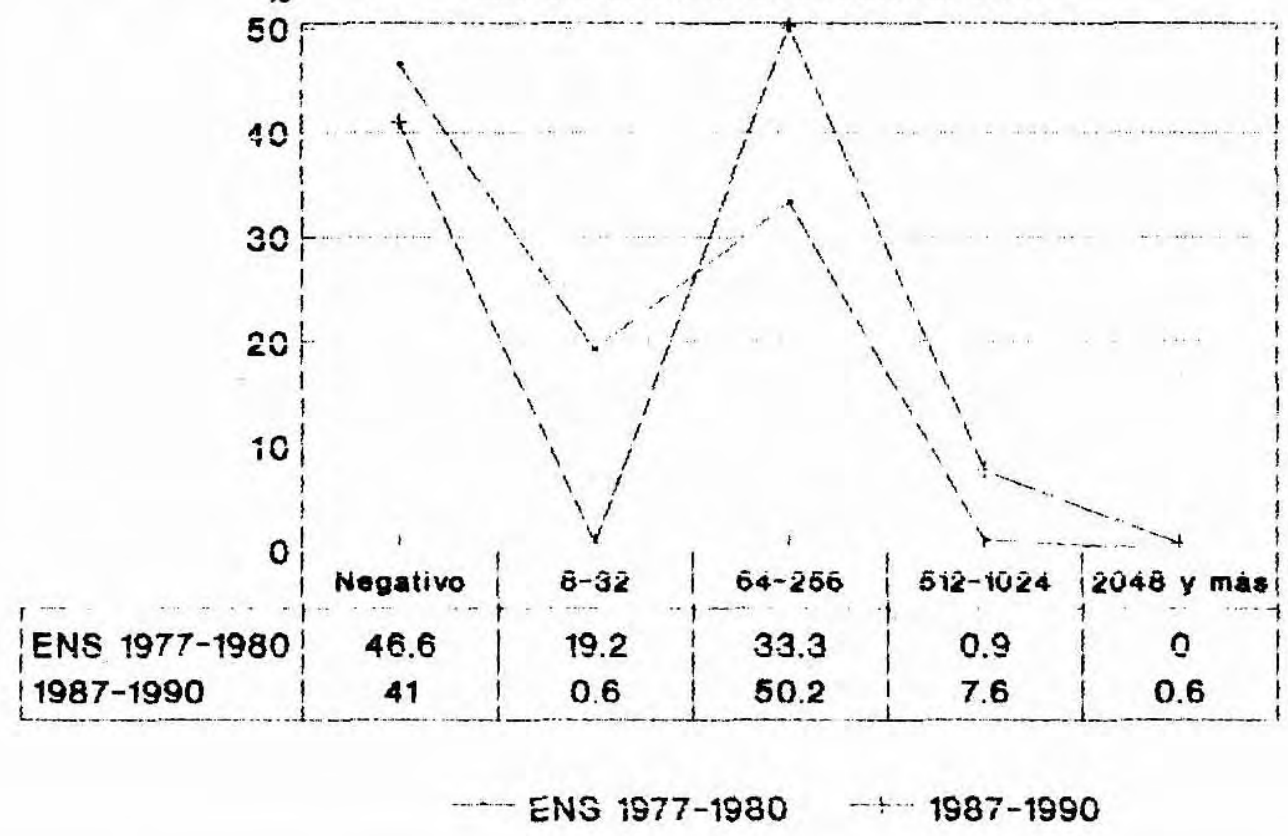




\section{DISCUSION}

En el presente trabajo se usó la prueba de Inmunofluorescencia Indirecta ya que ésta ha demostrado en innumerables estudios correlacionarse perfectamente con la prueba del colorante, prueba patrón (7).

El estudio muestra que asistieron a su primer control prenatal mujeres embarazadas en edades de 18 a 46 años, dentro de la quinta y la decimocuarta semana de embarazo. El $67.9 \%$ de las mujeres estaban entre los 25 y los 34 años de edad.

El 59\% de la población estudiada presentó positividad con títulos de 1:16 a 1:4.096. El $41 \%$ no presentó títulos, siendo ésta la población a riesgo, que no presentó ninguna seroconversión durante el embarazo.

Estudios anteriores realizados en otras partes del mundo muestran que el riesgo de adquirir toxoplasmosis durante el embarazo es del $0.4 \%$ en Suecia (8), del $1.6 \%$ en Sao Paulo (9), del $1.6 \%$ en el área de París (10) y en Colombia del $1.35 \%$ (3).

A diferencia de otro estudio donde se investigó el papel de la prevención primaria en la incidencia de la toxoplasmosis en las embarazadas y en el cual se redujo en parte ésta, debido a la dificultad de aplicar concienzudamente las medidas de higiene (11), en el presente trabajo no hubo ninguna seroconversión probablemente a causa del grado de instrucción de las pacientes, lo cual contribuyó a una mejor comprensión de las medidas preventivas.

La seroconversión de títulos de 1:256 y de 1:64 a negativos es explicable, ya que la técnica usada en este estudio sólo lee títulos a partir de $1: 16$ y es posible que las personas que se negativisaron, tuvieran títulos de 1:8 ó 1:4.

Destacamos el hecho de no haberse presentado seroconversión dentro de la población seronegativa en la cual aplicando el riesgo dado por el estudio nacional de salud (6) deberíamos esperar 2.24 serocoversiones y aplicando el dado por los estudios de Restrepo (2) y el de la Clínica David Restrepo (3) sería 11 y 1 seroconversiones respectivamente. Este resultado es debido, con una alta probabilidad, a las medidas preventivas que se suministraron, y por tanto recomendamos, al lado de la vigilancia serológica, dar educación sobre la prevención de la infección.

\section{SUMMARY}

Theincidence of Toxoplasmagondii infection was studied by the Parasitology Group of the Colombian National Institute of Health in sera from 1,000 pregnat women in prenatal control at the Caja Nacional de Previsión, from 1987 until 1990.

Specific IgG antibodies against Toxoplasma gondii were measured by the indirect immunofluorescence technique.

Fifty nine per cent (59\%) of the women were positive with titres ranging between 1:16 to $1: 4,096$. This figure agrees with those of the First National Health Survey. Forty one per cent $(41 \%)$ of the woman population was negative; none of the seronegative women seroconverted, yielding an incidence of 0 in the studied group.

All pregnant women were instructed about preventive measures to avoid the $T$. gondii infection during pregnancy, which showed a high effectiveness, since none of the seronegative patients seroconverted during pregnancy. Thus, it is highly advisable, to give education about the ways to prevent the infection, in addition to the serological follow-up.

\section{AGRADECIMIENTOS}

Los autores reconocen y agradecen la colaboración de la División de Investigaciones Especiales con la Estadística Laura de Romero en la revisión y análisis estadístico y al Ingeniero Adolfo Ardila en 1o referente a la computarización de los datos y al Grupo de Inmunología por el suministro del conjugado.

\section{BIBLIOGRAFIA}

1. Fernández M, Sibaja MT, Granier AR. Encuesta seroepidemiológica de anticuerpos anti Toxoplasma gondii en mujeres embarazadas del oriente del estado de Tabasco. Bol Med Hosp Infant Mex 1986; 43: 274. 
2. Restrepo M, Jaramillo V, Kurzer A. Infección por Toxoplasma gondii durante el embarazo. Ant Med 1976; 26: 347.

3. Romero J. El síndrome TORCH en Perinatología. Pediatría $1990 ; 25: 51$.

4. Center for Disease Control. Serology of Toxoplasmosis. In: Palmer DF, Cavallaro JJ, Walls K, Sulzer A, Wilson M, eds. Procedural guide revised. Georgia:U/S/Department of Health, education and Welfare 1976; 5:26. Inmunology Series N1.

5. Hebert GA, Pittman B, Nc Kinney RM, et al. The preparation and physicochemical characterization of fluorescent antibody reagentes. Georgia: Center Disease Control 1972; 1.

6. Juliao O,Corredor A,Moreno GS.Estudio Nacional de Salud: Toxoplasmosis en Colombia. Bogotá: Ministerio de Salud, Instituto Nacional de Salud, Asociación Colombiana de Facultades de Medicina 1983: 29.
7. Walton BC, Benchoff BM, Brook WH. Comparison of the indirect fluorescent antibody test and methylene blue dye test for detection of antibodies to Toxoplasma gondii. Am J Trop Med Hyg 1966; 15: 149.

8. Ahlfors $\mathbf{K}$, Borjeson M, Huldt $\mathbf{G}$, et al. Incidence of toxoplasmosis in pregnant women in the city of Malmo, Sweden. Cand J Infect Dis 1989; 21(3): 315.

9. Castilho EA. An estimation of the incidence of congenital toxoplasmosis in Sao Paulo City-Brasil. Rev Inst Med Trop S. Paulo 1976; 18: 205.

10. Jeanne D, Niel G, Costagliola D, et al. Epidemiology of toxoplasmosis among pregnant women in the Paris area. Int $\mathrm{J}$ Epidemiol 1988 Sep; 17: 595.

11. Foulon W, Naessens $\mathbf{A}$, Lauwers $\mathbf{S}$, et al. Impact of primary prevention on the incidence of toxoplasmosis during pregnancy. Obstet Gynecol 1988 Sep; 72 (3 Pt 1): 363-6. 